\title{
Nutritional advantages of probiotics and prebiotics
}

\author{
P. Marteau ${ }^{1,2,3 *}$ and M. C. Boutron-Ruault ${ }^{1,2}$ \\ ${ }^{1}$ ISTNA (INSERM U557-INRA U1125-EA CNAM 3200), ${ }^{2}$ Gastroenterology Department, \\ Hôpital Européen Georges Pompidou, Assistance Publique des Hôpitaux de Paris, France, \\ ${ }^{3}$ Paris V University, France
}

\begin{abstract}
The potential 'nutritional advantages' of probiotics and prebiotics consist of preventive, and sometimes curative, effects against certain diseases. The evidence supporting such advantages, which requires randomised controlled trials and consistency of results from study to study, is rapidly increasing. This article summarizes the effects against diseases of intestinal origin. There is a high level of evidence for positive effects of some prebiotics to alleviate constipation and treat hepatic encephalopathy. Interesting aspects, but with a lower level of evidence at the present time, include prevention of colon cancer, intestinal infection, and recurrence of inflammatory bowel disease. There is a high level of evidence for positive effects of some probiotics in the alleviation of lactose intolerance, antibiotic-associated intestinal disorders and gastroenteritis. Evidence is rapidly growing regarding the prevention of recurrence of inflammatory bowel diseases. Positive trials have suggested preventive effects against intestinal colonization with specific gut pathogens including Clostridium difficile and Helicobacter pylori.
\end{abstract}

Probiotics: Prebiotics: Disease prevention by food

\section{Introduction}

Probiotics have been defined as viable microbial food supplements which beneficially influence the health of the host (Schrezenmeir \& De Vrese, 2001). Prebiotics are food ingredients that are largely undegraded in the small bowel and can beneficially affect the host by selectively stimulating the growth and/or activity of one or a limited number of bacteria (Schrezenmeir \& De Vrese, 2001). In farm animals, probiotics and prebiotics may enhance growth and prevent early mortality, especially from infections (Huber, 1997; Mulder et al. 1997). In humans, their potential 'nutritional advantages' consist of preventative curative effects against diseases including intestinal dysfunctions, gastro-intestinal infections, inflammatory bowel disease and possibly colon cancer. The evidence supporting nutritional advantages of probiotics and prebiotics is rapidly increasing. Many studies now follow a pharmacological approach, and the rules of evidence-based medicine. The demonstration of a high or reasonable level of evidence requires randomized-controlled trials (RCT), and consistency of results from study to study. The effects of probiotics and prebiotics on mineral absorption, lipid metabolism, and cancer risk are discussed in other articles in the same issue of this journal, and the present article summarizes the effects against intestinal diseases (or diseases of intestinal origin).

\section{Do the nutritional advantages of prebiotics and probiotics differ?}

Although prebiotics and probiotics probably share common mechanisms of action (especially modulation of the endogenous flora), they differ in their composition and metabolism. The fate of prebiotics in the gastrointestinal tract is better known than that of probiotics. Prebiotics, like other low digestible carbohydrates, exert an osmotic effect in the gastrointestinal tract as long as they are not fermented; when they are fermented by the endogenous flora, i.e. at the place where they exhibit their prebiotic effect, they also increase intestinal gas production (Roberfroid \& Slavin, 2000). Prebiotics have therefore the theoretical risk to increase diarrhoea in some situations (because of the osmotic effect) and to be poorly tolerated in patients with irritable bowel syndrome. The tolerance of low doses of prebiotics is nevertheless usually excellent (Marteau \& Flourie, 2001). Probiotics do not have this theoretical drawback, and have often been effective to prevent or alleviate various clinical situations with diarrhoea.

\footnotetext{
Note: For the definition of the terms inulin and oligofructose please refer to the introductory paper (p. S139) and its footnote.

* Corresponding author: Professor P. Marteau, Service d'Hépato-Gastroentérologie, Hôpital Européen Georges Pompidou 20 rue Leblanc, 75908 Paris CEDEX 15, France, fax +33 15609 3554, email philippe.marteau@egp.ap-hop-paris.fr
} 


\section{Prebiotics}

\section{Demonstrated effects}

Alleviation of constipation. Low digestible carbohydrates with a low molecular weight exhibit a positive effect on intestinal transit in constipated patients. This is probably due not only to their osmotic effect but also to other mechanisms, which may include modulation of the indigenous microflora (Clausen \& Mortensen, 1997).

Treatment of hepatic encephalopathy. Several RCT have shown that lactulose and lactitol are superior to placebo to treat hepatic encephalopathy (Clausen \& Mortensen, 1997; Dhiman et al. 2000). The mechanisms involved include: bacterial incorporation of nitrogen and acidification of the colonic environment which in turn reduces the breakdown of nitrogen-containing compounds to ammonia and other potential cerebral toxins (Weber, 1996).

\section{Other potential applications \\ (lower level of evidence at the present time)}

Pre-clinical studies have suggested that prebiotics may have promising properties in inflammatory bowel disease (Szilagyi, 1998), prevention of cholesterol gallstones (Rotstein et al. 1981), and prevention of infections of intestinal origin (Dai \& Walker, 1999). Well controlled studies in patients are needed.

Protective effects against colon cancer have also been suggested. There is some experimental evidence that secondary bile salts are involved in colonic carcinogenesis, and that non digestible oligosaccharides can decrease the faecal concentration, probably through colonic $\mathrm{pH}$ reduction. Several animal studies have supported the hypothesis and even suggested that other mechanisms could be involved (Pool-Zobel et al. 2002). Roncucci et al. (1993) reported that lactulose decreased the recurrence rate of colonic adenomas. Two hundred and fiftyfive patients with colon adenomas were randomized after removal of the adenomas to receive vitamins, lactulose $(20 \mathrm{~g} / \mathrm{d})$ or no treatment. Colonoscopy was performed thereafter every 6 months. After a mean follow-up of 18 months, the percentages of recurrence of adenomas were $5.7 \%$ in the vitamin group, $14.7 \%$ in the lactulose group, and $35.9 \%$ in the untreated patients. Unfortunately, this study was not blinded and has not yet been confirmed.

\section{Probiotics}

\section{Demonstrated effects}

Improvement of lactose intolerance and other enzymatic effects. Lactose maldigestion is a frequent situation for many adults. Studies have demonstrated that digestion and tolerance are improved when lactose is ingested in yogurt containing live bacteria than when it is consumed in milk or heated yogurt (in which the bacteria have been killed during the heating process) (de Vrese et al. 2001). This effect is largely due to digestion of lactose in the gut lumen by lactase contained in yogurt bacteria and released in the small bowel when these bacteria are lysed by bile acids (Marteau et al. 1990). In clinical practice, replacement of milk by yogurt or fermented dairy products decreases or suppresses the symptoms of lactose intolerance (de Vrese et al. 2001).

Preliminary trials have suggested that sucrase or lipase could be delivered in the small bowel in subjects or animals with enzyme deficiency using natural or genetically modified probiotic vectors (Harms et al. 1987; Drouault et al. 2001). However, this way of delivery needs to be studied in more robust detail.

Antibiotic associated diarrhoea. Diarrhoea occurs in up to $20 \%$ of patients who receive antibiotics, and results from microbial imbalance. Several randomized doubleblind trials have demonstrated that Saccharomyces boulardii, Lactobacillus rhamnosus GG, and Enterococcus faecium SF68 are significantly more efficient than a placebo to decrease the risk of diarrhoea in healthy volunteers or patients receiving antibiotics (Marteau et al. 2001a; Szajewska et al. 2001; Armuzzi et al. 2001). The mechanism involved is unclear, and is in fact probably not unique. For example, oral administration of $S$. boulardii has been shown in humans or animals treated with antibiotics to decrease, in some cases, the colonization of the endogenous ecosystem by $C$. difficile, in other cases to decrease the toxin production by $C$. difficile, and in other experiments to protect the epithelial barrier function (Elmer et al. 1996; Czerucka et al. 2000). Other probiotic products may work as well but they have not (hitherto) been sufficiently well studied to reach a fair level of evidence.

Gastroenteritis. Gastroenteritis is a frequent disorder that heals, usually spontaneously, within a few days. Several RCT demonstrated a beneficial effect of L. rhamnosus GG in the treatment of infant diarrhoea, especially due to rotavirus infection (Guandalini et al. 2000; Marteau et al. 2001a). It was suggested in one study that heat inactivated $L$. rhamnosus was as effective as living $L$. rhamnosus on diarrhoea, however the effect of the living probiotic was more pronounced on rotavirus specific IgA response (Kaila et al. 1995). E. faecium SF 68 (Bioflorin ${ }^{\circledR}$, Giuliani, Switzerland) has also been shown to significantly shorten diarrhoea in four RCT. Other probiotics are probably also effective (Marteau et al. 2001a).

Saavedra et al. (1994) showed that the preventive feeding of Bifidobacterium bifidum and S. thermophilus to infants, admitted to hospital, significantly reduced the risk of diarrhoea and shedding of rotavirus. In a doubleblind placebo controlled trial, fifty-five children admitted to a chronic medical care unit were randomized to receive a standard formula or the same plus Bifidobacterium bifi$d u m$ and S. thermophilus. During follow up, diarrhoea occurred in $7 \%$ of the children receiving the probiotic versus $31 \%$ of the controls. The shedding of rotavirus was also reduced to $10 \%$ versus $39 \%$.

\section{Other potential applications (lower level of evidence at the present time)}

Inflammatory bowel disease (IBD). Inflammatory bowel diseases (IBD) are disorders of unknown cause characterized by chronic or recurrent intestinal inflammation. They include ulcerative colitis, Crohn's disease, 
Table 1. Results of randomized controlled trials which reported efficacy of probiotics in patients with inflammatory bowel disease

\begin{tabular}{|c|c|c|c|c|c|c|c|}
\hline Situation (prevention) & Probiotic & Control & $n$ & Duration & $\begin{array}{l}\text { Relapse: probiotic } \\
\text { group/control }\end{array}$ & $P$ & Reference \\
\hline Ulcerative colitis & E. coli Nissle 1917 & 5-ASA & 120 & 4 months & $16 \% / 11.3 \%$ & NS & Kruis et al. (1997) \\
\hline Ulcerative colitis & E. coli Nissle 1917 & 5-ASA & 120 & 12 months & $67 \% / 73 \%$ & NS & Rembacken et al. (1999) \\
\hline Ulcerative colitis & S. boulardii + 5-ASA & 5-ASA & 31 & 12 months & $30 \% / 35 \%$ & NS & Copaci et al. (2000) \\
\hline Pouchitis (chronic) & VSL \#3 & placebo & 40 & 9 months & $15 \% / 100 \%$ & $<0.05$ & Gionchetti et al. (2000a) \\
\hline Pouchitis & VSL \#3 & placebo & 40 & 12 months & $10 \% / 40 \%$ & $<0.05$ & Gionchetti et al. (2000b) \\
\hline $\begin{array}{l}\text { Crohn's disease } \\
\text { (post-operative } \\
\text { recurrence) }\end{array}$ & VSL \#3 & 5-ASA & 28 & 12 months & $20 \% / 40 \%$ & $<0.05$ & Campieri et al. (2000) \\
\hline Crohn's disease & E. coli Nissle 1917 & placebo & 28 & 12 months & $30 \% / 70 \%$ & $<0.05$ & Malchow (1997) \\
\hline Crohn's disease & S. boulardii + 5-ASA & 5-ASA alone & 28 & 6 months & $6.3 \% / 37.5 \%$ & $<0.05$ & Guslandi et al. (2000) \\
\hline
\end{tabular}

VSL\#3 (CSL, Milan, Italy) contains 300 billion viable lyophilized bacteria per gram of four strains of lactobacilli (L. casei, L. plantarum, L. acidophilus, L. delbrueckii subsp. bulgaricus), three strains of bifidobacteria (B. longum, B. breve, B. infantis), and one strain of Streptococcus salivarius subsp. thermophilus. 5-ASA: 5-aminosalicylic acid.

and pouchitis. The mechanisms responsible for initiation and perpetuation of the inflammatory process remains unknown but the main theory is that IBD may result from abnormal host responses to some members of the intestinal flora, and/or from a defective mucosal barrier (Shanahan, 2001). Several RCT have recently demonstrated that certain probiotics could be of great clinical interest and need to be further studied (Table 1). For some, the level of evidence is close to that needed for physicians to prescribe them to patients. Trials are on going and knowledge is progressing quickly in this field (for a review see Marteau \& Shanahan, in press).

Intestinal infections and colonisation by pathogenic bacteria. Protective effects of probiotics against intestinal infections have been demonstrated in animal models and seem to be an important mechanism for "nutritional advantages', i.e. growth stimulation and decrease in mortality (Huber, 1997; Mulder et al. 1997). The mechanisms that may be implicated include the production of acids, hydrogen peroxide, or antimicrobial substances, competition for nutrients or adhesion receptors, antitoxin actions, and stimulation of the immune system.

Studies have suggested a beneficial role of L. rhamnosus GG, S. boulardii and L. plantarum LP299v during Clostridium difficile related infections (see references in Marteau et al. 2001a). Two RCT have tested the efficacy of $S$. boulardii to decrease the risk of recurrence of $C$. difficile infection (McFarland et al. 1994; Surawicz et al. 2000). In the first trial, 124 patients were randomized to receive either $S$. boulardii (1 g/d for $28 \mathrm{~d}$ ) or a placebo, associated with the standard antibiotic treatment. The risk of clinical recurrence for the subjects with several episodes of $C$. difficile infection was significantly reduced in the $S$. boulardii group: $34.6 \%$ versus $64.7 \%(P=0.04)$. In the second study, a significant decrease in the risk of recurrence was observed in patients treated with a high dose of vancomycin plus $S$. boulardii versus a high dose of vancomycin plus placebo (Surawicz et al. 2000).

Helicobacter pylori is a good target for an efficient probiotic therapy. Colonization of the gastric mucosa is strongly associated with gastritis, duodenal and gastric ulcers, but also with lymphoma and carcinoma. Antagonistic actions of some Lactobacillus strains against $H$. pylori in vitro have been reported (Coconnier et al. 1998). A significant reduction of the urease activity has been reported in patients treated with a supernatant of $L$. johnsonii LA1 (Nestlé, Switzerland) associated with omeprazole (Michetti et al. 1999). Two RCT have recently reported that the ingestion of a fermented dairy product containing this strain or a heat killed Lactobacillus acidophilus could help to decrease the gastric colonization by $H$. pylori (Canducci et al. 2000; Felley et al. 2001). Further confirmation and proof of effect is needed.

Traveller's diarrhoea. Acute diarrhoea occurs in about half of travellers to high risk-areas. Several RCT were performed using probiotics (see references in Marteau et al. 2001a), however, their methodology was often insufficient (e.g. drop outs, statistics, end-points) such that no clear conclusion could be drawn.

Irritable bowel syndrome (IBS). Several authors have tested the effects of various probiotics in subjects with IBS. At the present time, the level of proof is low and the majority of trials were negative. It seems however, an interesting track as at least two RCT have shown that some probiotics could influence the transit time of healthy humans (Bouglé et al. 1999; Marteau et al. 2001b).

Colon cancer. Regular consumption of some probiotics may decrease the faecal levels of enzymes, mutagens, and secondary bile salts which may be involved in colonic carcinogenesis (Wollowski et al. 2001). Some, but not all, epidemiological studies have also suggested that consumption of fermented dairy products may have some protective effect against large colon adenomas or cancer (Boutron et al. 1996). Clinical studies are currently ongoing in Europe to study the effects of probiotics in subjects with colon adenomas.

\section{Concluding remarks}

Prebiotics and probiotics are obviously interesting agents in the field of preventive nutrition, and they should therefore have an important development. Positive effects have now clearly been demonstrated in specific fields with certain products. However, unreasonable extrapolation of results to other clinical situations, products or doses should be avoided. 


\section{References}

Armuzzi A, Cremonini F, Bartolozzi F, Canducci F, Candelli M, Ojetti V, Cammarota G, Anti M, De Lorenzo A, Pola P \& Gasbarrini G \& Gasbarrini A (2001) The effect of oral administration of Lactobacillus GG on antibiotic-associated gastrointestinal side-effects during Helicobacter pylori eradication therapy. Alimentary Pharmacology and Therapeutics 15, $163-169$.

Bouglé D, Roland N, Lebeurrier F \& Arhan P (1999) Effect of propionibacteria supplementation on fecal bifidobacteria and segmental colonic transit time in healthy human subjects. Scandinavian Journal of Gastroenterology 34, 144-148.

Boutron MC, Faivre J, Marteau P, Couillault C, Senesse P \& Quipourt V (1996) Calcium, phosphorus, vitamin D, dairy products and colorectal carcinogenesis: a French case-control study. British Journal of Cancer 74, 145-151.

Campieri M, Rizzello F, Venturi A, Poggioli G, Ugolini F \& Helwig U, et al. (2000) Combination of antibiotic and probiotic treatment is efficacious in prophylaxis of post-operative recurrence of Crohn's disease: a randomized controlled study vs mesalamine (abstract). Gastroenterology 118, G4179.

Canducci F, Armuzzi A, Cremonini F, Cammarota G, Bartolozzi F, Pola P, Gasbarrini G \& Gasbarrini A (2000) A lyophilized and inactivated culture of Lactobacillus acidophilus increases Helicobacter pylori eradication rates. Alimentary Pharmacology and Therapeutics 14, 1625-1629.

Clausen MR \& Mortensen PB (1997) Lactulose, disaccharides and colonic flora. Clinical consequences. Drugs 53, 930-942.

Coconnier MH, Lievin V, Hemery E \& Servin AL (1998) Antagonistic activity against Helicobacter infection in vitro and in vivo by the human Lactobacillus acidophilus strain LB. Applied and Environmental Microbiology 64, 4573-4580.

Copaci I, Micu L, Chira C \& Rovinaru I (2000) Maintenance of remission of ulcerative colitis (UC): mesalamine, dietary fiber, S. boulardii (abstract). Gut 47(suppl III), A240-P929.

Czerucka D, Dahan S, Mograbi B, Rossi B \& Rampal P (2000) Saccharomyces boulardii preserves the barrier function and modulates the signal transduction pathway induced in enteropathogenic Escherichia coli-infected T84 cells. Infection and Immunity 68, 5998-6004.

Dai D \& Walker WA (1999) Protective nutrients and bacterial colonization in the immature human gut. Advances in Pediatrics 46, 353-382.

de Vrese M, Stegelmann A, Richter B, Fenselau S, Laue C \& Schrezenmeir J (2001) Probiotics-compensation for lactase insufficiency. American Journal of Clinical Nutrition 73(2 Suppl), 421S-429S.

Dhiman RK, Sawhney MS, Chawla YK, Das G, Ram S \& Dilawari JB (2000) Efficacy of lactulose in cirrhotic patients with subclinical hepatic encephalopathy. Digestive Disease and Science 45, 1549-1552.

Droualt S, Juste C, Marteau P, Renault P \& Corthier G (2001) Genetically modified Lactococcus lactis expressing Staphylococcus hyicus lipase enhance lipid digestion in pigs with pancreatic insufficiency (abstract). Gastroenterology 20, G3642.

Elmer GW, Surawicz CM \& McFarland LV (1996) Biotherapeutic agents. A neglected modality for the treatment and prevention of selected intestinal and vaginal infections. Journal of the American Medical Association 275, 870-876.

Felley CP, Corthesy-Theulaz I, Rivero JL, Sipponen P, Kaufmann M, Bauerfeind P, Wiesel PH, Brassart D, Pfeifer A, Blum AL \& Michetti P (2001) Favourable effect of an acidified milk (LC-1) on Helicobacter pylori gastritis in man. European Journal of Gastroenterology and Hepatology 13, 25-29.

Gionchetti P, Rizzello F, Venturi A, Brigidi P, Matteuzzi D \& Bazzocchi G, et al. (2000a) Oral bacteriotherapy as maintenance treatment in patients with chronic pouchitis: a double-blind, placebo-controlled trial. Gastroenterology 119, 305-309.

Gionchetti P, Rizzello F, Venturi A, Helwig U, Amadini C \& Lammers KM, et al. (2000b) Prophylaxis of pouchitis onset with probiotic therapy: a double blind, placebo controlled trial (abstract). Gastroenterology 118, G1214.

Guandalini S, Pensabene L, Zikri MA, Dias JA, Casali LG, Hoekstra H, Kolacek S, Massar K, Micetic-Turk D, Papadopoulou A, de Sousa JS, Sandhu B, Szajewska H \& Weizman Z (2000) Lactobacillus GG administered in oral rehydration solution to children with acute diarrhea: a multicenter European trial. Journal of Pediatrics Gastroenterology and Nutrition 30, 54-60.

Guslandi M, Mezzi G, Sorghi M \& Testoni PA (2000) Saccharomyces boulardii in maintenance treatment of Crohn's disease. Digestive Diseases and Science 45, 1462-1464.

Harms HK, Bertele-Harms RM \& Bruer-Kleis D (1987) Enzyme substitution therapy with the yeast Saccharomyces cerevisiae in congenital sucrase-isomaltase deficiency. New England Journal of Medicine 316, 1306-1309.

Huber JT (1997) Probiotics in cattle. In Probiotics, pp. 162-185 [R Fuller, editor]. London: Chapman \& Hall.

Kaila M, Isolauri E, Saxelin M, Arvilommi H \& Vesikari T (1995) Viable versus inactivated Lactobacillus strain GG in acute rotavirus diarrhoea. Archives of Diseases of Childhood 72, 51-53.

Kruis W, Schütz E, Fric P, Fixa B, Judmaier G \& Stolte M (1997) Double-blind comparison of an oral Escherichia coli preparation and mesalazine in maintaining remission of ulcerative colitis. Alimentary Pharmacology and Therapeutics 11, 853-858.

Malchow HA (1997) Crohn's disease and Escherichia coli. A new approach in therapy to maintain remission of colonic Crohn's disease? Journal of Clinical Gastroenterology 25, 653-658.

Marteau P, Flourié B, Pochart P, Chastang C, Desjeux JF \& Rambaud JC (1990) Role of the microbial lactase (EC 3.2.123) activity from yogurt on the intestinal absorption of lactose: an in vivo study in lactase deficient humans. British Journal of Nutrition 64, 71-79.

Marteau P \& Flourie B (2001) Tolerance to low-digestible carbohydrates: symptomatology and methods. British Journal of Nutrition 85(Suppl 1), S17-S21.

Marteau PR, de Vrese M, Cellier CJ \& Schrezenmeir J (2001a) Protection from gastrointestinal diseases with the use of probiotics. American Journal of Clinical Nutrition 73(2 Suppl), 430S-436S

Marteau P, Cuillerier E, Gerhardt MF, Myara A, Bouvier M, Bouley C, Méance S, Bommelaer G \& Grimaud JC (2001b) Bifidobacterium animalis strain DN-173 010 shortens the colonic transit time in healthy women: a double blind randomised controlled study. Alimentary Pharmacology \& Therapeutics. In press.

Marteau P \& Shanahan F (2002) Role of antibiotics and probiotics in the management of inflammatory bowel disease. In Inflammatory Bowel Disease: From Bench to Bedside, 2nd edition. In press.

McFarland LV, Surawicz CM, Greenberg RN, Fekety R, Elmer GW, Moyer KA, Melcher SA, Bowen KE, Cox JL \& Noorani $\mathrm{Z}$, et al. (1994) A randomized placebo-controlled trial of Saccharomyces boulardii in combination with standard antibiotics for Clostridium difficile disease. Journal of the American Medical Association 271, 1913-1918.

Michetti P, Dorta G, Wiesel PH, Brassart D, Verdu E, Herranz M, Felley C, Porta N, Rouvet M, Blum AL \& CorthesyTheulaz I (1999) Effect of whey-based culture supernatant of Lactobacillus acidophilus (johnsonii) La1 on Helicobacter pylori infection in humans. Digestion 60, 203-209. 
Mulder R, Havenaar R \& Huis in't Veld J (1997) Intervention strategies: the use of probiotics and competitive exclusion microfloras agaisnt contamination with pathogens in pigs and poultry. In Probiotics, pp. 186-208 [R Fuller, editor]. London: Chapman \& Hall.

Pool-Zobel B, Van Loo J, Rowland I \& Roberfroid M (2002) Experimental evidences on the potential of prebiotic fructans to reduce the risk of cancer. British Journal of Nutrition 87, S273-S281, this issue.

Rembacken BJ, Snelling AM, Hawkey PM, Chalmers DM \& Axon AT (1999) Non-pathogenic Escherichia coli versus mesalazine for the treatment of ulcerative colitis: a randomised trial. Lancet 354, 635-639.

Roberfroid M \& Slavin J (2000) Nondigestible oligosaccharides. Critical Review of Food Science and Nutrition 40, 461-480.

Roncucci L, Di Donato P, Carati L, Ferrari A, Perini M, Bertoni G, Bedogni G, Paris B, Svanoni F \& Girola M (1993) Antioxidant vitamins or lactulose for the prevention of the recurrence of colorectal adenomas. Diseases of the Colon and Rectum 36, 227-234.

Rotstein OD, Kay RM, Wayman M \& Strasberg SM (1981) Prevention of cholesterol gallstones by lignin and lactulose in the hamster. Gastroenterology 81, 1098-1103.

Saavedra JM, Bauman NA, Oung I, Perman JA \& Yolken RH (1994) Feeding of Bifidobacterium bifidum and Streptococcus thermophilus to infants in hospital for prevention of diahrroea and shedding of rotavirus. Lancet 344, 1046-1049.
Schrezenmeir J \& de Vrese M (2001) Probiotics, prebiotics, and synbiotics- approaching a definition. American Journal of Clinical Nutrition 73(2 Suppl), 361S-364S.

Shanahan F (2001) Inflammatory bowel disease: immunodiagnostics, immunotherapeutics, and ecotherapeutics. Gastroenterology 120, 622-635.

Surawicz CM, McFarland LV, Greenberg RN, Rubin M, Fekety $\mathrm{R}$, Mulligan ME, Garcia RJ, Brandmarker S, Bowen K, Borjal D \& Elmer GW (2000) The search for a better treatment for recurrent Clostridium difficile disease: use of high-dose vancomycin combined with Saccharomyces boulardii. Clinical Infectious Diseases 31, 1012-1017.

Szajewska H, Kotowska M, Mrukowicz JZ, Armanska M \& Mikolajczyk W (2001) Efficacy of Lactobacillus GG in prevention of nosocomial diarrhea in infants. Journal of Pediatrics 138, 361-365.

Szilagyi A (1998) Altered colonic environment, a possible predisposition to colorectal cancer and colonic inflammatory bowel disease: rationale of dietary manipulation with emphasis on disaccharides. Canadian Journal of Gastroenterology 12, 133-146.

Weber FL Jr (1996) Lactulose and combination therapy of hepatic encephalopathy: the role of the intestinal microflora. Digestive Disease 14(Suppl 1), 53-63.

Wollowski I, Rechkemmer G \& Pool-Zobel BL (2001) Protective role of probiotics and prebiotics in colon cancer. American Journal of Clinical Nutrition 73(Suppl. 2), 451S-455S. 